\title{
PRODUCING AND MANIPULATING INFORMATION
}

\author{
ROBERT A. J. DUR \\ OTTO H. SWANK
}

CESIFO WORKING PAPER NO. 908

CAtegory 2: Public Choice

APRIL 2003

\footnotetext{
An electronic version of the paper may be downloaded

- from the SSRN website: www.SSRN.com

- from the CESifo website: www.CESifo.de
} 


\title{
PRODUCING AND MANIPULATING INFORMATION
}

\begin{abstract}
To reduce the chances of policy failures, policy makers need information about the effects of policies. Sometimes, policy makers can rely on agents who already possess the information. Often, the information has yet to be produced. This raises two problems. First, for a policy maker it is hard to ascertain how much effort an expert has put in acquiring information. Second, when the expert has an interest in the policy outcome, she may manipulate information to bring the policy decision more in line with her preferences. We show that experts who are unbiased toward the policy alternatives put highest effort in collecting information. Eliminating manipulation of information, however, requires that the preferences of the policy maker and the expert are aligned. Hence, when selecting an expert, policy makers face a trade-off. We show that policy makers optimally appoint experts with policy preferences which are less extreme than their own.
\end{abstract}

JEL Code: D78, D82, D83.

Robert A. J. Dur

Erasmus University

$\mathrm{FEW} / \mathrm{H} \mathrm{7-21}$

P.O. Box 1738

3000 DR Rotterdam

The Netherlands

dur@few.eur.nl
Otto H. Swank

Otto Swank

Erasmus University

FEW / H 7-13

P.O. Box 1738

3000 DR Rotterdam

The Netherlands

This is an extended and completely revised version of TI Discussion Paper 2001-052/1. Part of the research was done while Dur was visiting CES Munich. Their generous hospitality is gratefully acknowledged. We thank the Editor and two anonymous referees for useful comments on previous versions. Dur gratefully acknowledges financial support from NWO, KNAW, and VSNU through a Vernieuwingsimpuls grant. 


\section{Introduction}

Policy makers have to make many decisions of which the consequences are complicated and difficult to foresee. Because of a lack of time and abilities, it is virtually impossible for members of parliament, ministers, or a president to become well informed about the consequences of all their decisions.

Division of labor may help to solve this problem. This is reflected in the organization of the political decision making process. An essential feature of the organization of the government is specialization. Political executives are organized into ministries. Legislature are organized into jurisdictions. A well-known reason for specialization is that it facilitates information collection.

Specialization, however, also creates serious agency problems. First, specialization may lead to a situation where informed agents have disproportionate influence in a policy area. Information about the consequences of policies is usually hard to verify by policy makers. The unverifiablity of information leaves room for informed agents to manipulate information or to frame their recommendations. Thus, informed agents often acquire effective control over decisions, even if they do not have formal authority for selecting actions (Aghion and Tirole, 1997).

Second, it is often hard for policy makers to ascertain the effort the agents have put in producing information. Devoting more resources to producing information is supposed to lead to a recommendation which is based on better information. The quality of information is, however, hard to observe. Better information does not always lead to thicker reports (large models are not always better than small ones).

This paper studies the selection of information collecting agents by policy makers in the light of these agency problems. We analyze who, in a group of heterogeneous agents, are appointed to collect information and to give policy recommendations.

We examine a model in which a decision maker (parliament, a president, a minister) has to choose between two alternatives: implementation and status quo. The consequences of the project are surrounded by uncertainty. Without further information, the decision maker runs the risk of making a wrong decision. He can appoint an agent to collect information about the consequences of the project and to make a recommendation. We refer to this agent as the expert. One could think of this expert as an homogeneous legislative committee or a public agency. The expert 
promotes what she perceives as the public interest. Her perception of the public interest may deviate from that of the decision maker. After the expert has made a recommendation about the project, the decision maker decides whether or not to implement the project.

The focus of the analysis is on the collection of information and the transmission of information. Our model treats information as a good with the following characteristics. First, the production of information involves costly effort. Second, the production of information is uncertain. In spite of her effort, the expert may make mistakes. The probability of making mistakes decreases in the expert's effort. Third, the expert's effort - and thus the quality of information - is not observed by the policy maker. Fourth, the information obtained by the expert can not be verified by the policy maker. Hence, when making a decision, the policy maker must rely on the expert's recommendation (or possibly manipulated information).

The weak link between information and the recommendation implies that it is hard for the decision maker to ascertain the effort the expert has put in producing information. The non-verifiability of information leaves room for an expert to frame her recommendation. The first problem leads to uncertainty about the quality of information on which a recommendation is based. The second problem leads to uncertainty about the quality of the recommendation, given the quality of information.

We derive three main results. First, we show that the effort an expert puts in collecting information depends on her perception of the public interest. An expert who has a strong prior either against or in favor of the project exerts less effort than an expert who is unbiased. The intuition is that strong priors reduce the probability that information affects advice. The instrumental value of information is therefore small for experts with strong priors. An implication of this result is that by appointing an expert who is unbiased toward one of the policy alternatives, the decision maker maximizes the effort put in producing information.

Our second result is that, given the information produced by the expert, the quality of the recommendation depends negatively on the difference between the decision maker's and the expert's perception of the public interest. This result is in line with the existing literature on communication (Crawford and Sobel, 1982). By appointing an expert whose perception of the public interest coincides with his own perception, the decision maker maximizes the quality of the recommendation, given 
the quality of the information produced by the expert.

Together the above results imply that, when the decision maker can select an expert on the basis of her perception of the public interest, then he faces a tradeoff between the quality of the recommendation and the quality of the information the recommendation is based on. We show that it is in the interest of the decision maker to appoint an expert whose perception of the public interest deviates from his own perception, except for the special case where the decision maker is neither biased toward implementation of the project nor biased toward status quo. If the decision maker is at least somewhat biased, he will appoint an expert who is less biased so as to increase the quality of information.

Our study is related to the the literature on the role of information providers in the policy-decision process. Games of incomplete information are used to study communication between an uninformed policy maker and an informed agent (see, for example, Austen-Smith, 1990 and 1993). As the present paper, this literature is based on the assumption that the informed agent has a vested interest in the policy outcome (Milgrom and Roberts, 1986). Models of communication are applied to interest groups (Potters and Van Winden, 1992), to bureaucrats (for a survey, see Lupia and McCubbins, 1998), voters (Lohmann, 1993), and committee members (Gilligan and Krehbiel, 1987 and 1989). The focus of this literature is on information transmission. A well-known result is that, if there are no costs of supplying information, information transmission requires that the interests of the policy maker and the information provider are not too far apart (Crawford and Sobel, 1982). ${ }^{1} \mathrm{Kr}-$ ishna and Morgan (2001) illustrate this point for the case in which a decision maker consults two experts. Ottaviani and Sorensen (2001) examine a model of expertise in which experts care about their reputation. They show that reputational concerns may lead to herding problems.

Our theoretical contribution is that we relax the assumption of a specific distribution of information among agents. Although this assumption is natural in situations where agents possess information as a by-product of their normal activities, it is less natural in situations where decision makers need information which does not exist yet. Endogenizing information collection has important and potentially

\footnotetext{
${ }^{1}$ If supplying information is costly, information transmission depends less on the congruence of preferences [for a survey of the signaling literature see Banks (1991)].
} 
testable consequences. Krehbiel (1992) argues that legislative committees will not be composed of preference outliers. In his study on legislative organization, outlier means that the preferences of the expert deviate from the preferences of the median member of the group. In our analysis, experts are outliers in the sense of Krehbiel, if the median member of the group is at least somewhat biased towards one of the policy alternatives.

The result that policy makers appoint outliers so as to increase the quality of information becomes even stronger when information is verifiable. The reason is that the quality of recommendation does no longer depend on the adviser's perception of the public interest when information is hard. We show that if the policy maker is biased in favour of implementing the project and information is hard, he appoints an adviser who has strong priors against implementation, and vice versa. The intuition is straightforward. The stronger an adviser is biased in opposite direction, the more she wants to prevent the policy maker from choosing the policy alternative in line with his priors. The only way to accomplish this is to come up with a piece of evidence which convinces the policy maker that he should not follow his prior belief. The probability to find such a piece of evidence increases in the adviser's effort. We also study the case where advisers always learn some information of which the content is verifiable but the quality is not. In that case, the adviser's opportunity to conceal information has the same implications as the opportunity to manipulate information in the case of unverifiable information.

The paper is organized as follows. Section 2 presents the model. Section 3 analyzes the interaction between the decision maker and an expert being responsible for acquiring information. In Section 4, the decision maker selects an expert on the basis of her preferences. Section 5 examines cases of verifiable information. Section 6 concludes.

\section{The Model}

We consider a situation where citizens delegate the decision about a public project, $X$, to a policy maker. As to this project, there are two alternatives: implementation (denoted by $X=1$ ) and status quo (denoted by $X=0$ ). We assume that the policy maker tries to make a decision which accords with his perception of the 
public interest. If the policy maker chooses implementation his payoff increases with $p+\mu$, where $p$ denotes the expected social benefit of the project as perceived by the policy maker, and $\mu$ is a stochastic term, which is distributed by $f(\mu)$. The expected value of $\mu$ is zero. The cumulative distribution of $\mu$ is denoted by $F(\mu)$. Our interpretation of $\mu$ is that the consequences of the project are surrounded by uncertainty. If the policy maker chooses $X=0$, his payoff does not change.

Under full information, the policy maker would choose $X=1$ if $\mu>-p$, and $X=0$ if $\mu \leq-p .^{2}$ However, the policy maker does not observe $\mu$. The implication is that without information about $\mu$ the policy maker would choose $X=1$ if $p>0$, and $X=0$ if $p \leq 0$. It is evident that, if $0<F(-p)<1$, then the policy maker runs the risk of making a wrong decision about the project.

The policy maker lacks time or abilities to examine $\mu .^{3}$ To gain information about $\mu$, the policy maker can hire an adviser. ${ }^{4}$ An adviser receives a signal $\gamma$, which may contain information about $\mu$. The quality of the adviser's signal depends on her effort $e \geq 0$, which cannot be observed by the policy maker. With probability $\pi(e)$, the signal is fully informative, implying $\gamma=\mu$, where $\pi(e)$ is increasing and concave and $\pi(0)=0$. With probability $1-\pi(e)$, the signal is uninformative. Then, $\gamma$ is drawn from $f(\gamma)$. Except when $e=0$, neither the adviser nor the policy maker knows whether or not the signal is informative. ${ }^{5}$ The adviser is effort averse. Her cost of supplying effort is $c(e)$. The function $c(e)$ is increasing and convex, with $c(0)=0$.

After receiving the signal, the adviser makes a recommendation. She can either recommend $X=1$ or recommend $X=0$. Communication between the policy maker and the adviser is limited to the recommendation made by the adviser. Information is thus soft: it cannot be instantaneously verified by the policy maker. In Section 5 we examine the case where information is hard. Restricting the message space to two messages is without loss of generality, because the model revolves around a

\footnotetext{
${ }^{2}$ Without loss of generality, we assume that if the policy maker is indifferent between implementation and status quo, he chooses status quo.

${ }^{3}$ We thus assume that producing information requires expertise the policy maker does not possess. For less complicated decisions, the policy maker can choose to specialize (Gilligan and Krehbiel, 1989)

${ }^{4}$ We assume that the policy maker cannot hire more than one adviser.

${ }^{5}$ The assumption that $\pi(e)>0$ for $e>0$ is made for convenience. The assumption ensures an interior solution of effort. The free-rider problem concerning the production of information becomes more profound if $\pi(e)=0$ for $e<\bar{e}>0$.
} 
binary decision. Consequently, irrespective of her type, the adviser either prefers implementation or status quo. Thus, with two possible messages, what needs to be said can be said. If we had assumed a richer message space, we would also have found a binary equilibrium.

Like the policy maker, an adviser is concerned with the public interest. However, because of differences in normative values or ideology, the adviser's perception may differ from that of the policy maker. If the policy maker hires an adviser and chooses $X=1$, then the payoff to the adviser is $a+\mu-c(e)$, where $a$ denotes the expected social benefit of the project as perceived by the adviser. If the status quo is maintained, then the payoff to the adviser is $-c(e)$. The difference between $a$ and $p$ reflects the difference between the policy maker's and the adviser's perception of the public interest.

Since information is soft in our model, the recommendation made by the adviser is "cheap talk" (Crawford and Sobel, 1982). It is well-known that in cheap-talk games several equilibria may exist. We focus on an equilibrium in which information transmission between the players is possible. Moreover, we assume a "natural" language, in the sense that the adviser's recommendation always reflects her preferred action

\section{Adviser's Effort and Policy Recommendation}

Suppose that the policy maker always follows the adviser's recommendation. It is then optimal for the adviser to recommend $X=1$ if $X=1$ yields a higher expected payoff, conditional on $\gamma$, than $X=0$. The adviser thus recommends $X=1$ if $\pi(e)(a+\gamma)+[1-\pi(e)] a>0$, implying:

$$
\gamma>-\frac{a}{\pi(e)}
$$

Equation (1) gives the evaluation criterion used by the adviser. If the policy maker had received a signal about $\mu$, he would have chosen $X=1$ if $\gamma>-\frac{p}{\pi(e)}$, and $X=0$ otherwise. Hence, only when $a=p$, there is perfect communication between the policy maker and the adviser. If $a>p$, there is a risk that the adviser recommends implementation while status quo would be optimal for the policy maker, and vice 
versa.

When the adviser chooses effort, her expected payoff is:

$$
\begin{aligned}
& \pi(e)\left[1-F\left(-\frac{a}{\pi(e)}\right)\right]\left[a+\frac{-\frac{a}{\pi(e)}}{1-F\left(-\frac{a}{\pi(e)}\right)}\right]+ \\
& {[1-\pi(e)]\left[1-F\left(-\frac{a}{\pi(e)}\right)\right] a-c(e)}
\end{aligned}
$$

The first two terms of (2) give the expected benefits of effort. The last term gives the cost of effort. Maximizing (2) with respect to $e$ yields: ${ }^{6}$

$$
\pi^{\prime}(e) \int_{-\frac{a}{\pi(e)}} \mu f(\mu) \mathrm{d} \mu=c^{\prime}(e)
$$

Equation (3) implicitly defines the adviser's optimal level of effort, $e^{*}$, as a function of $a, e^{*}=e^{*}(a)$. The implicit function theorem applied to (3) shows that $e_{a}^{*}(0)=0$, $e_{a}^{*}<0$ for $a>0$, and $e_{a}^{*}>0$ for $a<0$. These findings imply that an adviser who is "unbiased" $(a=0)$ exerts most effort. The more the adviser is biased toward one of the policy choices, the less effort she will make. The intuition is straightforward. The probability that, without information about $\mu$, the adviser makes a costly mistake decreases with the absolute value of $a$. The reason is that the probability that information about $\mu$ changes the adviser's preferences over policies is small when she is strongly biased. As a consequence, the expected benefits of information decrease with $|a|$.

So far, we have assumed that the policy maker follows the adviser's recommendation. Let us now identify the conditions under which it is optimal for the policy maker to follow this strategy. Given the adviser's strategy, it is optimal for the policy maker to choose $X=1$ when the adviser recommends $X=1$, if implementation yields a higher expected payoff than status quo. It is easy to verify that this

\footnotetext{
${ }^{6}$ Throughout, we assume that the second-order condition for a maximum is satisfied. This requires that the absolute value of $a$ is not too large.
} 
requires:

$$
p>-\frac{\pi\left(e^{*}\right) \int_{-\frac{a}{\pi\left(e^{*}\right)}} \mu f(\mu) \mathrm{d} \mu}{1-F\left(-\frac{a}{\pi\left(e^{*}\right)}\right)}
$$

Analogously, we can show that it is optimal for the policy maker to choose status quo when the adviser recommends status quo if:

$$
p \leq-\frac{\pi\left(e^{*}\right) \int^{-\frac{a}{\pi\left(e^{*}\right)}} \mu f(\mu) \mathrm{d} \mu}{F\left(-\frac{a}{\pi\left(e^{*}\right)}\right)}
$$

Clearly, if $a=p$, then it is always optimal for the policy maker to follow the adviser's recommendation. Given effort, the more $a$ deviates from $p$, the lower is the payoff to the policy maker. Conditions (4) and (5) therefore imply that it is only optimal for the policy maker to follow the adviser's recommendation if $a$ does not deviate too much from $p$. Clearly, the conditions become less restrictive, the higher the value of $\pi\left(e^{*}\right)$ and the lower $|p|$.

\section{The Optimal Adviser from the Policy Maker's Point of View}

In the previous section we have shown that the adviser's perception of the public interest determines her effort level. Thus, $a$ affects the quality of information on which policy decisions are based. In addition, we have shown that $a$ affects the quality of the recommendation. If $a$ deviates from $p$, then the recommendation made by the adviser may be inconsistent with the policy maker's preferences. In this section we derive the optimal value of $a$ from the policy maker's perspective. The idea is that the policy maker can create a public agency with monopoly power and can shape its preferences by appointing a head with the appropriate perception of the public interest.

What value of $a$ is optimal for the policy maker? To answer this question, we 
use (1) to write the expected payoff to the policy maker as a function of $a$ :

$$
\left[1-F\left(-\frac{a}{\pi\left(e^{*}\right)}\right)\right] p+\pi\left(e^{*}\right) \int_{-\frac{a}{\pi\left(e^{*}\right)}} \mu f(\mu) \mathrm{d} \mu
$$

After differentiating (6) with respect to $a$, and using (3), we can write the first-order condition as:

$$
f\left(-\frac{a}{\pi\left(e^{*}\right)}\right) Z(p-a)=e_{a}^{*} c^{\prime}\left(e^{*}\right)
$$

where

$$
Z=\frac{a \pi^{\prime}\left(e^{*}\right) e_{a}^{*}-\pi\left(e^{*}\right)}{\left[\pi\left(e^{*}\right)\right]^{2}}<0
$$

Equation (7) implicitly defines the optimal value of $a, a^{*}$, as a function of $p$.

Proposition 1 If $p=0$, then $a^{*}=0$. If $p>0$, then $0<a^{*}<p$. If $p<0$, then $p<a^{*}<0$.

Proof. Using (3), it is easy to see that if $p=0$, then condition (7) is satisfied iff $a^{*}=0$. The proof for the other two cases is by contradiction. Suppose $p>0$. If $a^{*} \geq p$, then the LHS of (7) is greater than or equal to zero, while the RHS is smaller than zero. Hence, $a^{*}<p$. If $a^{*} \leq 0$, then the RHS of $(7)$ is greater than or equal to zero, while the LHS is smaller than zero. Hence, $a^{*} \geq 0$. When $a=p$, always following advice yields a higher expected payoff than always ignoring advice. Since $a=a^{*}$ yields a higher expected payoff than $a=p$, it is optimal for the policy maker to follow advice (restriction 5 is satisfied). Hiring an adviser whose recommendation might not be followed reduces the adviser's incentive to search for information while the adviser's incentive to manipulate information remains the same. The proof for the case that $p<0$ is analogous.

Proposition 1 says that a policy maker who is biased toward implementation (status quo) consults an expert who is less biased toward implementation (status quo) than himself. Against the background of our earlier result that the effort level depends negatively on $|a|$, the above proposition is hardly surprising. Recall that the policy maker consults an adviser in order to avoid a policy failure. In the present 
model, imperfect communication and a wrong signal received by an adviser are the possible reasons for a policy failure. By appointing an adviser whose perception of the public interest coincides with that of himself, the policy maker prevents a policy failure owing to imperfect communication. By appointing an adviser with $a=0$, the policy maker minimizes the probability that the adviser receives an incorrect signal about $\mu$. The proposition shows that when the policy maker selects an adviser, he faces a trade-off between the quality of information and the quality of recommendations.

Our insight is related to Gilligan and Krehbiel's (1987, 1989) analysis of the congressional committee system. They argue that only committee members with moderate preferences have an incentive to specialize, i.e. to produce information. In their work, however, moderate preferences mean preferences closely aligned to the preferences of the median member in Congress. Their argument refers to the credibility of advice, i.e. the quality of the recommendations, given the quality of information. Our analysis shows that there is also another story. Moderate preferences, in the sense of no strong bias toward implementation or status quo, induces a adviser to look harder for information.

\section{Verifiable Information}

In this section, we examine the implications of changing our assumptions about the nature of information. First, we examine a situation in which the policy maker can freely verify information, but the adviser can choose to conceal information, as in Milgrom and Roberts (1986). Next, we analyze the case where information is verifiable and the adviser's effort determines the probability with which a signal is observed instead of the quality of the signal, as in Dewatripont and Tirole (1999). We show that our results of the previous sections are robust to the first modification but not to the second one.

\subsection{Opportunity to Conceal Information}

The introduction of freely verifiable information which can be concealed extends the message space. Apart from recommending $X=0$ and recommending $X=1$, the adviser can conceal information, i.e. be silent. 
To analyze the implications of verifiable information, let us first determine when the adviser wants to conceal information. First consider the case that $a<p$. Then, an adviser wants to conceal information if (1) $\gamma \in\left[-\frac{p}{\pi(e)},-\frac{a}{\pi(e)}\right)$ and (2) concealing information induces the policy maker to choose $X=0$. Does it make sense for an adviser to conceal information if $\gamma \in\left[-\frac{p}{\pi(e)},-\frac{a}{\pi(e)}\right)$ ? The answer to this question is in the affirmative, provided that the adviser never recommends $X=0$. To see why, first note that, if $\gamma>-\frac{a}{\pi(e)}$, then it is in the interest of the adviser to recommend $X=1$. The policy maker, who can verify information, will respond by choosing $X=1$. Now suppose that the adviser recommends $X=0$ if $\gamma \leq-\frac{p}{\pi(e)}$. Again, the policy maker will follow his adviser when he learns that $\gamma \leq-\frac{p}{\pi(e)}$. However, from the adviser's strategy, the policy maker can infer that when the adviser is silent, $\gamma \in\left[-\frac{p}{\pi(e)},-\frac{a}{\pi(e)}\right)$. Concealment of information thus induces the policy maker to choose $X=1$. It is easy to verify that if the adviser's strategy is "be silent" when $\gamma \leq-\frac{a}{\pi(e)}$, and recommend $X=1$ when $\gamma>-\frac{a}{\pi(e)}$, then it is optimal for the policy maker to choose $X=1$ when the adviser recommends $X=1$ and to choose $X=0$ when the adviser is silent. But this set of stategies is equivalent to the equilibrium set of strategies discussed in Section 3, except that now the adviser is silent rather than recommends $X=0$ when $\gamma \leq-\frac{a}{\pi(e)}$.

In a similar way, we can show that in case $a>p$ an equilibrium exists in which (1) the adviser is silent when $\gamma>-\frac{a}{\pi(e)}$, and recommends $X=0$ when $\gamma \leq-\frac{a}{\pi(e)}$ and (2) the policy maker chooses $X=0$ when the adviser recommends $X=0$, and chooses $X=1$ otherwise. Hence, we can conclude that the introduction of verifiable messages together with the opportunity of concealment of information by the adviser only affects the nature of the adviser's messages. It neither affects effort, nor the policy maker's choice of his adviser. ${ }^{7}$

\subsection{Effort-dependent Learning of Information}

In this subsection, we modify the information production process to deepen our understanding of the driving forces behind our argument. Instead of assuming that

\footnotetext{
${ }^{7}$ Results change when advisers can not conceal verifiable information. Then, on a range of $a$ in the neighbourhood of $p$, advisers have the same incentive to exert effort, while advisers outside this range are not willing to participate. Clearly, advisers' policy preferences only affect their effort if they have an opportunity to put a stamp on policy decisions, either by manipulation or by concealment of information.
} 
the adviser always observes a signal of which the quality depends on his effort, we follow Dewatripont and Tirole (1999) in assuming that the adviser's effort determines the probability with which a fully informative signal is observed. In case of unverifiable messages, this modification is innocuous. When the adviser's signal can be verified, results change dramatically. Without affecting the results, we assume that information can not be concealed.

The adviser has to expend effort to observe $\mu$. We assume that with probability $\pi(e)$, the adviser learns $\mu$. Since information can neither be concealed nor manipulated, if the adviser learns $\mu$, then the policy maker learns $\mu$ as well. With probability $1-\pi(e)$, the adviser learns nothing. We address two questions. First, how does effort depend on $a$ with hard information? Second, what are the consequences of hard information for the optimal type of adviser?

To answer these questions, let us first consider the strategy of the policy maker. If the adviser does not learn $\mu$, the policy maker has to make a decision about $X$ without information about $\mu$. Consequently, he will choose $X=1$ if $p>0$ and $X=0$ if $p \leq 0$. If the adviser learns $\mu$, then the policy maker learns $\mu$ as well. Consequently, the policy maker chooses $X=1$ if $\mu>-p$ and $X=0$ otherwise.

Let us now turn to the adviser. When information is hard, the adviser does not make a recommendation. She only determines how much effort to put in information collection. Suppose $p<0$. The adviser anticipates that the project will be implemented if and only if she finds evidence that $\mu>-p$. Her expected payoff when selecting effort is:

$$
\pi(e)[1-F(-p)]\left[a+\frac{\int \mu p f(\mu) \mathrm{d} \mu}{1-F(-p)}\right]-c(e)
$$

It is easy to verify that the first-order condition for a maximum of (9) defines $e$ as a function of $a$ and $p$. Application of the implicit function theorem shows that $e$ increases with both $a$ and $p$. The intuition is clear. The policy maker chooses $X=0$ if he does not receive further information about $\mu$, as $p<0$. The stronger an adviser is biased towards implementation, the more the adviser wants to prevent the policy maker from choosing $X=0$. The only way to convince the policymaker to choose $X=1$ is to show that $\mu>-p$. The probability that the adviser finds such a piece 
of evidence increases in her effort. The reason that effort is increasing in $p$ is that the higher is $p$ (given that $p<0$ ), the higher is the probability that the adviser finds that $\mu>-p$.

Now suppose $p>0$. Then, without information about $\mu$, the decision maker chooses $X=1$. The expected payoff to the adviser as a function of $e$ is equal to:

$$
\pi(e)[1-F(-p)]\left[a+\frac{\int-p}{1-F(-p)}\right]+[1-\pi(e)] a-c(e)
$$

We can show that $e$ is decreasing in $a$ and $p$. Hence, the more an adviser is biased against the project, the more effort she puts in information collection.

The above results have obvious consequences for the policy maker's choice of adviser. With verifiable information, the credibility of the message is not important. Only effort matters. The policy maker should therefore appoint an adviser who has an opposite perception of the public interest.

\section{Concluding Remarks}

This paper has studied the delegation of information collection by policy makers to policy-motivated experts. The analysis has centered on two agency problems: the uncertainty about the effort experts put in producing information and the risk that experts manipulate information or frame their recommendation. We have shown that the more an expert is biased toward one of the policy alternatives, the weaker her incentive to produce information. Hence, to maximize the quality of information, the policy maker should rely on unbiased experts. However, if the policy maker is biased toward one of the policy alternatives, unbiased experts manipulate information. To maximize the quality of the recommendation, the preferences of the policy maker and the expert should coincide. In selecting an expert, the policy maker thus faces a tradeoff between the quality of the recommendation and the quality of the information the recommendation is based on. We have shown that policy makers optimally appoint experts who are biased in the same direction as the policy maker but less extremely than the policy maker.

An important assumption underlying our analysis is that information about the 
effects of policies is not easily verified by policy makers because of a lack of time or expertise on the part of policy makers. Although we believe that this is a typical feature of the policy making process, policy makers may occasionally be experts themselves or have acquired expertise over time, and hence may be less vulnerable to manipulation of information. This may change the optimal selection of policy motivated experts depending on the characteristics of the information production process. In the case where an adviser always learns information of which the quality depends on her effort, results are unaffected as long as the adviser has the opportunity to conceal information. However, when the discovery of information is dependent on effort, policy makers optimally appoint experts who are strongly biased in the direction opposite to the policy maker's bias. The intuition is that these experts have the strongest incentive to convince the policy maker not to choose the policy alternative in line with the policy maker's priors. The expert's effort increases the probability the she discovers information that can convince the policy maker.

We have made several simplifying assumptions about the political process. Particularly, we have assumed that the policy decision is delegated to a single individual, and that this individual is only concerned with outcomes. The implication of these assumptions is that the only reason why a policy maker consults advisers is to avoid policy failures. In reality, often several policy makers are involved in making policy decisions. The implication is that a policy maker may want to consult an adviser to persuade other policy makers to support his policy proposals (Swank, Letterie and Van Dalen, 1999). Introducing elections into the model may also affect our results. Elections may induce policy makers to consult advisers to justify policies, rather than to obtain information. Moreover, distortions in the election process may imply that the optimal adviser from the policy maker's point of view is different from the optimal adviser from the electorate's point of view.

\section{References}

Aghion, Philippe, and Tirole, Jean (1997), Formal and Real Authority in Organizations, J ournal of Political Economy, 105(1), February 1997, pp. 1-29.

Austen-Smith, David (1990), Information Transmission in Debate, American J ournal of Political Science, 34, pp. 124-152. 
Austen-Smith, David (1993), Interested Experts and Policy Advice: Multiple Referrals under Open Rule, Games and Economic Behavior, 5(1), January 1993, pp. 3-43.

Banks, Jeffrey S. (1991), Signaling Games in Political Science, New York: Harwood Academic.

Crawford, Vincent P., and Sobel, Joel (1982), Strategic Information Transmission, Econometrica, 50(6), November 1982, pp. 1431-1451.

Dewatripont, Mathias, and Tirole, Jean (1999), Advocates, J ournal of P olitical Economy, 107(1), February 1999, pp. 1-39.

Gilligan, Thomas W., and Krehbiel, Keith (1987), Collective Decisionmaking and Standing Committees: An Informational Rationale for Restrictive Amendment Procedures, J ournal of Law, Economics and Organization, 3(2), Fall 1987, pp. 287335.

Gilligan, Thomas W., and Krehbiel, Keith (1989), Collective Choice without Procedural Commitment, In: Ordeshook, Peter C. (Ed.), M odels of Strategic Choice in Politics, Ann Arbor: University of Michigan Press, pp. 295-314.

Gilligan, Thomas W., and Krehbiel, Keith (1997), Specialization Decisions Within Committee, J ournal of Law, Economics, and Organization, 13, pp. 366-386.

Krehbiel, Keith (1992), Information and Legislative Organization, Ann Arbor: University of Michigan Press.

Krishna, Vijay, and Morgan, John (2001), A Model of Expertise, Quarterly J ournal of Economics, 116, pp. 747-775.

Lohmann, Susanne (1993), A Signaling Model of Informative and Manipulative Political Action, American Political Science Review, 87(2), June 1993, pp. 319-333.

Lupia, Arthur, and McCubbins, Mathew D. (1998), The Democratic Dilemma: Can Citizens Learn W hat They Really Need to K now?, Cambridge: Cambridge University Press.

Milgrom, Paul, and Roberts, John (1986), Relying on the Information of Interested Parties, Rand J ournal of Economics, 17, pp. 18-32.

Ottaviani, Marco, and Sorensen, Peter (2001), Information Aggregation in Debate: Who Should Speak First?, J ournal of Public Economics, 81, pp. 393-421.

Potters, Jan, and Van Winden, Frans (1992), Lobbying and Asymmetric Information, Public Choice, 74(3), October 1992, pp. 269-292. 
Swank, Otto H., Letterie, Wilko, and Van Dalen, Hendrik P. (1999), An Economic Theory of Policy Advice, J ournal of Law, Economics, and Organization, 15(3), October 1999, pp. 602-614. 


\title{
CESifo Working Paper Series
}

\author{
(for full list see www.cesifo.de)
}

841 Robert Fenge and Martin Werding, Ageing and the Tax Implied in Public Pension Schemes: Simulations for Selected OECD Countries, January 2003

842 Robert Fenge and Martin Werding, Ageing and Fiscal Imbalances Across Generations: Concepts of Measurement, January 2003

843 Giovanni Andrea Cornia, The Impact of Liberalisation and Globalisation on Income Inequality in Developing and Transitional Economies, January 2003

844 Peter Fredriksson and Per Johansson, Program Evaluation and Random Program Starts, January 2003

845 Bernd Hayo and Matthias Wrede, Fiscal Equalisation: Principles and an Application to the European Union, January 2003

846 Syed M. Ahsan and Jaideep Oberoi, Inequality, Well-being and Institutions in Latin America and the Caribbean, January 2003

847 Chang Woon Nam and Doina Maria Radulescu, The Role of Tax Depreciation for Investment Decisions: A Comparison of European Transition Countries, January 2003

848 V. Bhaskar and Steinar Holden, Wage Differentiation via Subsidised General Training, January 2003

849 Paloma Lopez-Garcia, Labour Market Performance and Start-up Costs: OECD Evidence, January 2003

850 Christian Keuschnigg and Soren Bo Nielsen, Public Policy for Start-up Entrepreneurship with Venture Capital and Bank Finance, January 2003

851 Yin-Wong Cheung, Menzie D. Chinn, and Eiji Fujii, China, Hong Kong, and Taiwan: A Quantitative Assessment of Real and Financial Integration, January 2003

852 Gregory D. Hess, The Economic Welfare Cost of Conflict: An Empirical Assessment, February 2003

853 Douglas J. Cumming and Jeffrey G. MacIntosh, Comparative Venture Capital Governance. Private versus Labour Sponsored Venture Capital Funds, February 2003

854 Eckhard Janeba and John Douglas Wilson, Decentralization and International Tax Competition, February 2003

855 Tapio Palokangas, Capital Accumulation and Employment Cycles in a Model of Creative Destruction, February 2003 
856 Brendan Walsh, When Unemployment Disappears: Ireland in the 1990s, February 2003

857 Luis H. R. Alvarez and Erkki Koskela, A General Approach to the Stochastic Rotation Problem with Amenity Valuation, February 2003

858 Christian Schultz, Strategic Campaigns and Redistributive Politics, February 2003

859 Ernst Fehr and Joseph Henrich, Is Strong Reciprocity a Maladaptation? On the Evolutionary Foundations of Human Altruism, February 2003

860 Haizhou Huang, Dalia Marin, and Chenggang Xu, Financial Crisis, Economic Recovery and Banking Development in Former Soviet Union Economies, February 2003

861 Pedro Cardoso and Bernard M.S. van Praag, How Sustainable Are Old-age Pensions in a Shrinking Population with Endogenous Labour Supply?, February 2003

862 Volker Meier, Efficient Transfer of Aging Provisions in Private Health Insurance, February 2003

863 Edward Castronova, Theory of the Avatar, February 2003

864 Robert S. Chirinko, Hans van Ees, Harry Garretsen, and Elmer Sterken, Investor Protections and Concentrated Ownership: Assessing Corporate Control Mechanisms in the Netherlands, February 2003

865 Bernard M.S. van Praag and Pedro Cardoso, The Mix Between Pay-as-you-go and Funded Pensions and what Demography has to do with it, February 2003

866 Ernst Fehr, Urs Fischbacher, Bernhard von Rosenbladt, Jürgen Schupp, and Gert G. Wagner, A Nation-Wide Laboratory. Examining Trust and Trustworthiness by Integrating Behavioral Experiments into Representative Survey, February 2003

867 Frank Heinemann, The Inflationary Impact of Wage Indexation, February 2003

868 Eytan Sheshinski, Bounded Rationality and Socially Optimal Limits on Choice in a Self-Selection Model, February 2003

869 M. Hashem Pesaran, Estimation and Inference in Large Heterogenous Panels with Cross Section Dependence, February 2003

870 Luis H. R. Alvarez and Erkki Koskela, On the Tree-Cutting Problem under Interest Rate and Forest Value Uncertainty, February 2003

871 Norbert Berthold and Rainer Fehn, Unemployment in Germany: Reasons and Remedies, February 2003

872 Clemens Fuest, Bernd Huber, and Philipp Tilleßen, Tax Policy and Entrepreneurship in the Presence of Asymmetric Information in Capital Markets, February 2003

873 Eytan Sheshinski, Optimum and Risk-Class Pricing of Annuities, February 2003 
874 Willi Leibfritz, Paul O'Brien and Jean-Christophe Dumont, Effects of Immigration on Labour Markets and Government Budgets - An Overview, February 2003

875 M. Hashem Pesaran and Allan Timmermann, How Costly is it to Ignore Breaks when Forecasting the Direction of a Time Series?, February 2003

876 Thorvaldur Gylfason and Gylfi Zoega, Education, Social Equality and Economic Growth: A View of the Landscape, February 2003

877 Robin Boadway and Jean-François Tremblay, Public Economics and Startup Entrepreneurs, February 2003

878 Erkki Koskela and Roope Uusitalo, The Un-Intended Convergence: How the Finnish Unemployment Reached the European Level, February 2003

879 Robert Fenge and Volker Meier, Pensions and Fertility Incentives, February 2003

880 Eytan Sheshinski, Note on Income Taxation and Occupational Choice, February 2003

881 A B Atkinson, Income Inequality in OECD Countries: Data and Explanations, February 2003

882 Thomas Gehrig and Rune Stenbacka, Venture Cycles: Theory and Evidence, February 2003

883 Ralf Becker and Thomas Hellmann, The Genesis of Venture Capital - Lessons from the German Experience, March 2003

884 Eytan Sheshinski, Note on the Optimum Pricing of Annuities, March 2003

885 Paul De Grauwe and Magdalena Polan, Globalisation and Social Spending, March 2003

886 F. van der Ploeg, Do Social Policies Harm Employment and Growth?, March 2003

887 Mirjam van Praag, Initial Capital Constraints Hinder Entrepreneurial Venture Performance: An empirical analysis, March 2003

888 Bernard Steunenberg, Coordinating Sectoral Policymaking: Searching for Countervailing Mechanisms in the EU Legislative Process, March 2003

889 Eytan Sheshinski, Optimum Delayed Retirement Credit, March 2003

890 Frederick van der Ploeg, Rolling Back the Public Sector - Differential effects on employment, investment and growth, March 2003

891 Paul De Grauwe and Marc-Alexandre Sénégas, Monetary Policy in EMU when the Transmission is Asymmetric and Uncertain, March 2003

892 Steffen Huck and Kai A. Konrad, Strategic Trade Policy and the Home Bias in Firm Ownership Structure, March 2003 
893 Harry Flam, Turkey and the EU: Politics and Economics of Accession, March 2003

894 Mathias Hoffmann and Ronald MacDonald, A Re-examination of the Link between Real Exchange Rates and Real Interest Rate Differentials, March 2003

895 Badi H. Baltagi, Espen Bratberg, and Tor Helge Holmås, A Panel Data Study of Physicians' Labor Supply: The Case of Norway, March 2003

896 Dennis C. Mueller, Rights and Citizenship in the European Union, March 2003

897 Jeremy Edwards, Gains from Trade in Tax Revenue and the Efficiency Case for Trade Taxes, March 2003

898 Rainer Fehn and Thomas Fuchs, Capital Market Institutions and Venture Capital: Do They Affect Unemployment and Labour Demand?, March 2003

899 Ronald MacDonald and Cezary Wójcik, Catching Up: The Role of Demand, Supply and Regulated Price Effects on the Real Exchange Rates of Four Accession Countries, March 2003

900 R. Selten, M. Schreckenberg, T. Pitz, T. Chmura, and S. Kube, Experiments and Simulations on Day-to-Day Route Choice-Behaviour, April 2003

901 Stergios Skaperdas, Restraining the Genuine Homo Economicus: Why the Economy Cannot be Divorced from its Governance, April 2003

902 Yin-Wong Cheung, Menzie D. Chinn, and Antonio Garcia Pascual, What Do We Know about Recent Exchange Rate Models? In-Sample Fit and Out-of-Sample Performance Evaluated, April 2003

903 Mika Widgrén, Enlargements and the Principles of Designing EU - Decision-Making Procedures, April 2003

904 Phornchanok Cumperayot, Dusting off the Perception of Risk and Returns in FOREX Markets, April 2003

905 Kai A Konrad, Inverse Campaigning, April 2003

906 Lars P. Feld and Stefan Voigt, Economic Growth and Judicial Independence: Cross Country Evidence Using a New Set of Indicators, April 2003

907 Giuseppe Bertola and Pietro Garibaldi, The Structure and History of Italian Unemployment, April 2003

908 Robert A.J. Dur and Otto H. Swank, Producing and Manipulating Information, April 2003 